\title{
Prevalence and predictors of adult hypertension in Kabul, Afghanistan
}

Khwaja Mir Islam Saeed ${ }^{1 *}$, Mohammad Hafez Rasooly ${ }^{1}$ and Nick JW Brown ${ }^{2,3,4}$

\begin{abstract}
Background: The prevalence of hypertension is rising worldwide with an estimated one billion people now affected globally and is of near epidemic proportions in many parts of South Asia. Recent turmoil has until recently precluded estimates in Afghanistan so we sought, therefore, to establish both prevalence predictors in our population.

Methods: We conducted a cross-sectional study of adults $\geq 40$ years of age in Kabul from December 2011-March 2012 using a multistage sampling method. Additional data on socioeconomic and lifestyle factors were collected as well as an estimate of glycaemic control. Bivariate and multivariable analyses were undertaken to explore the association between hypertension and potential predictors.

Results: A total of 1183 adults (men 396, women 787) of $\geq 40 y e a r s$ of age were assessed. The prevalence of hypertension was $46.2 \%$ ( $95 \% \mathrm{Cl} 43.5$ - 49.3). Independent predictors of hypertension were found to be: age $\geq 50$ $(\mathrm{OR}=3.86,95 \% \mathrm{Cl}: 2.86-5.21)$; illiteracy $(\mathrm{OR}=1.90,1.05-1.90)$; the consumption of rice $>3$ times per week $(\mathrm{OR}=1.43,1.07-1.91)$; family history of diabetes $(\mathrm{OR}=2.20,1.30-3.75)$; central obesity $(\mathrm{OR}=1.67,1.23-2.27)$; $\mathrm{BMI} \geq 30 \mathrm{Kg} /$ meter squared $(\mathrm{OR}=2.08,1.50-2.89)$. The consumption of chicken and fruit more than three times per week were protective with ORs respectively of 0.73 (0.55-0.97) and $0.64(0.47-0.86)$.

Conclusions: Hypertension is a major public health problem in Afghan adults. We have identified a number of predictors which have potential for guiding interventions.
\end{abstract}

Keywords: Prevalence, Associated factors, Blood pressure, Hypertension, Urban, Afghanistan

\section{Background}

High blood pressure is at epidemic levels globally. An estimated 1 billion people are affected [1-3] with particularly high prevalence in parts of South Asia thought to be a result of a combination of genetic susceptibility and lifestyle transition $[4,5]$. Predictors of hypertension in High Income Countries (HIC) include family history, age, race, obesity, physical inactivity, lack of exercise, cigarette smoking, excessive salt intake and excessive alcohol intake $[2,3]$.

In Afghanistan, due to years of conflict, it has been impossible to make any robust estimates of non-communicable disease prevalence. There is, however, no reason to believe that Afghans are less susceptible to non-communicable disease and estimates are therefore urgently required. The purpose of this study was to

\footnotetext{
* Correspondence: kmislamsaeed@gmail.com

'Surveillance/DEWS Directorate, Afghan National Public Health Institute (ANPHI), Ministry of Public Health, 3rd Floor, Room \# 9, Massoud Square, Kabul, Afghanistan

Full list of author information is available at the end of the article
}

estimate the prevalence of hypertension and assess the predictors in urban Afghan adults.

\section{Methods}

We conducted a cross-sectional study between December 2011 and March 2012 to estimate the prevalence of hypertension and its associated factors in Kabul. All adults aged 40 years and over who had been residing for at least one year or more in the 17 districts of Kabul city were eligible. The city has approximately 3,289,000 inhabitants living in 17 residential districts made up of neighborhoods (Gozar) comprised of 534,900 households [6]. We requested the Kabul municipality to provide a list of all neighborhoods and their representatives and were able to study 13 districts. To balance considerations of cost, resources, and time without compromising the representativeness of the sample, a two-phase cluster sampling technique was used as follows. Eligible subjects were selected by multistage sampling: in the first stage, a sample of neighborhoods 
was selected randomly from each district. In the second stage, a main masjid (mosque) was selected as a hallmark and heads of households around the masjid were asked to approach the team settled there. Finally, one adult from each household was randomly selected and interviewed after written consent was obtained.

Sample size estimation was based on a prior specified precision level of $5 \%$ and the assumption that the proportion of potential risk was similar to other studies conducted in other similar settings. We adjusted for intracluster correlation and concluded that 1,200 participants would be required.

One member from each household aged 40 years and over was interviewed using a proforma designed for the study. Height and weight were measured by measurement tape and electronic weighing scale. Using standard international criteria, we defined a BMI of $\geq 30 \mathrm{~kg} / \mathrm{m} 2$ as obese and a BMI of $25-30 \mathrm{~kg} / \mathrm{m} 2$ as overweight. A BMI of 18.5 to $25 \mathrm{~kg} / \mathrm{m} 2$ was considered normal. A waist circumference of $\geq 94 \mathrm{~cm}$ for men and $\geq 80 \mathrm{~cm}$ for women were considered centrally obese $[7,8]$.

Blood pressure was measured by twice by android sphygmomanometer in the sitting position on the left arm. Before analysis, blood pressure was dichotomized to hyper- or normotension by either systolic of $\geq 140 \mathrm{mmHg}$, or diastolic of $\geq 90 \mathrm{mmHg}$, or both. Those already on treatment were considered hypertensive irrespective of our own readings. Fasting blood sugar was tested using portable glucometer once in the morning before breakfast and analysed by the glucose oxidase method (check-ref). Data was single entered and, after cleaning, analysis was undertaken on 1,183 individuals [9]. Data on potential covariates such as: age, sex, ethnicity, family history of the disease, educational status, income, residential area, obesity, diabetes mellitus, smoking status, snuff using, physical activity and dietary behavior were collected through the structured pretested and modified questionnaire. No questions were made about alcohol as Afghanistan is an Islamic state and alcohol is considered a narcotic and is illegal. For normally distributed variables, we calculated mean and Standard Deviation (SD). For categorical variables we used chi-Squared and logistic regression and derived both uni- and multivariate estimates of Odds Ratios (OR) and 95\% Confidence Interval (95\% CI). Data were analyzed using SPSS 20 [10].

Ethical approval was obtained from the Institutional Review Board (IRB) of the Ministry of Public Health, Afghanistan.

\section{Results}

Descriptive data (Table 1)

The mean age of the study subjects was 49.5 years and most (59.3\%) were aged between 40 and 50 years. Sixty eight percent of the participants were ethnic Tajik and
20.7\% were ethnic Pashtuns. Two thirds were female. Most study participants were illiterate with a monthly income of 2,000 to 6,000 Afghanis (AFN) (One USD = $50 \mathrm{AFN})$. Forty percent of participants were unemployed or were casual laborers, while $25 \%$ of respondents were women engaged in home employ. Twenty two percent were government employees and the rest were engaged in the agricultural industry as farmers. Approximately $3.3 \%$ of respondents were retired and too old to engage in physical labor. $83 \%$ of participants had no knowledge of hypertension but only $14 \%$ were smokers. The prevalence of either systolic or diastolic hypertension was 46.2\% (95\% CI 43.5 - 49.3). The distribution of both systolic and diastolic blood pressure can be reviewed in Figures 1 and 2.

\section{Multivariate analysis}

Hypertension was associated with age but not gender. Literacy was protective (OR for illiteracy $=1.9095 \%$ CI: $1.05-1.90$ and P value $<0.05$ ) but level of income, smoking status and knowledge of diseases were not predictive. Unemployment and inability to work predicted hypertension ORs $=2.04$ (95\% CI: $1.49-2.78)$ and 1.69 ( $95 \%$ CI: $1.20-2.38$ ) respectively. The results for bivariate analysis can be reviewed in Table 2 and for multivariate analysis in Table 3.

\section{Discussion}

Our study shows a prevalence of hypertension in Kabuli adults of close to $50 \%$, which is comparable to that in many HIC settings. Predictors included illiteracy, obesity, low levels of physical activity and a family history of diabetes. A higher dietary quality (measured by higher chicken and fruit intake) had a modest protective effect but given the attenuation in the multivariate model it is possible that this association is simply a marker for other social factors. In keeping with the natural history of hypertension, prevalence increased with age.

Strengths of the study include the breadth of sampling across the city and two stage methods.

Our study is unique in Afghanistan in which any research over the last 15 years has been near impossible as a result of chronic warfare and instability.

Limitations of the study include the sampling. For logistical reasons our study was household rather than community based and, therefore, less likely to be involved in regular work. It is possible that the participants were less active or different in other ways to their employed counterparts and may, therefore, not have been representative of all Kabuli adults. We would have liked to undertake more comprehensive assessment of glucose tolerance but were precluded by budgetary constraints.

Our findings were consistent with work in similar settings. In rural Nepal, Khan showed that a high BMI 
Table 1 Frequency distribution of the demographic, socioeconomic characteristics and behavior factors of study participants $(n=1183)$

\begin{tabular}{l} 
Variables \\
\hline Age in years \\
$40-49$ \\
$50-59$ \\
$60-69$ \\
70 and over \\
Sex \\
Males \\
Females \\
Level of education \\
Illiterate \\
Primary/Unofficial education \\
Secondary school \\
High school and more \\
Monthly income \\
$\leq 10000$ \\
10000 - 20000 \\
20000 - 30000 \\
$\geq 30000$ \\
Work status \\
Government employee \\
Business \\
Jobless \\
Unable to work \\
Housewife
\end{tabular}

Knowledge of blood pressure

Yes

No

Smoking status

Current smoker

Ever smoker

Never smoker

Basic mass index

Underweight

Normal weight

Obese

Overweight

Type of cooking fat

Solid cooking fat

Liquid cooking fat

Other

Frequency of eating meat in a month

$<3$ times per month

$3-6$ time per month

Numbers (\%)

$691(59.3)$

$242(20.7)$

$159(13.6)$

$74(6.3)$

$396(33.5)$

$787(66.5)$

657 (57.1)

$118(9.9)$

$216(18.3)$

$174(14.7)$

$524(52.4)$

$293(29.3)$

$80(7.3)$

$103(10.3)$

$260(22.7)$

$59(5.2)$

$63(5.5)$

$472(41.3)$

$290(25.3)$

$195(16.5)$

$988(83.5)$

$61(5.2)$

$95(8.1)$

$1018(86.7)$

$13(1.1)$

346 (29.6)

365 (31.2)

$445(38.1)$

821 (69.6)

339 (28.6)

$4(1.8)$

307 (26.3)

$592(50.4)$
Table 1 Frequency distribution of the demographic, socioeconomic characteristics and behavior factors of study participants $(\mathbf{n}=\mathbf{1 1 8 3})$ (Continued)

6-9 times per month

$160(13.6)$

$\geq 9$ times per month

$116(9.9)$

Frequency of eating rice in a month

$<3$ times per month

$536(49)$

$3-6$ time per month

$432(39.5)$

6 - 9 times per month

$126(11.5)$

Frequency of taking vegetable in a month

Once a week

$240(20.3)$

Twice a week

$291(24.6)$

Thrice a week

$166(14)$

$>3$ times a week

$486(41.1)$

Frequency of taking fruits in a month

Once a week

$181(15.3)$

Twice a week

257 (22.6)

Thrice a week

233 (19.7)

>3times a week

$502(42.4)$

Mode of transportation to job

Walk by foot

747 (63.2)

Bicycle

$25(2.1)$

Motorcycle

$15(1.3)$

Car

$72(6.1)$

Public transport

$59(5)$

Frequency of physical activity

$<10$ minutes per day

$1022(86.4)$

10 - 30minutes per day

$132(11.2)$

$\geq 30$ minutes per day

$29(2.4)$

Frequency of sitting in hours

$<1$ hours per week

$238(20.1)$

10 - 30hours per week

$812(68.8)$

$\geq 30$ hours per week

$131(11.1)$

Frequency of walking in hours

$<$ 10hours per week

$375(31.9)$

10 - 30hours per week

625 (53.1)

$\geq 30$ hours per week

176 (15)

\section{Blood pressure}

Normotensive

$573(48.5)$

Pre-Hypertensive

$218(18.4)$

Hypertensive

$392(33.1)$

General obesity

Yes

$379(32)$

$804(68)$

Central obesity

$687(58.8)$

Yes

$481(41.2)$ 


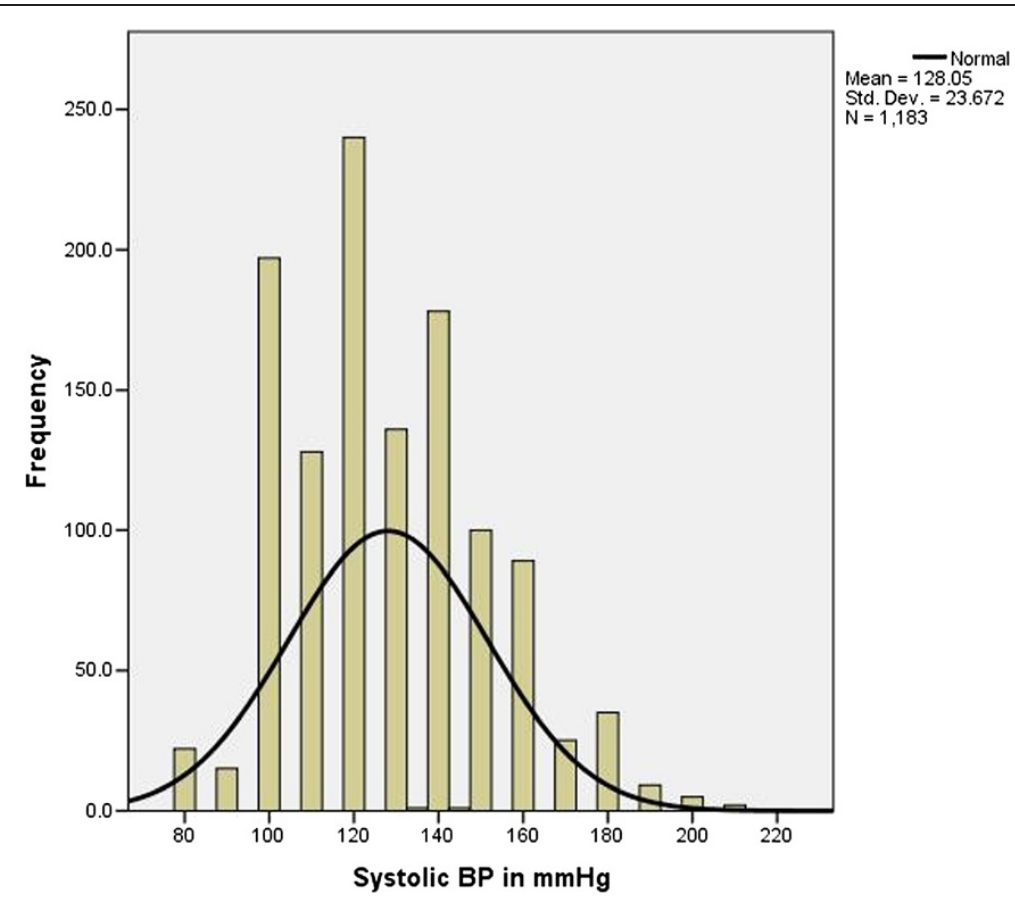

Figure 1 Graphic (histogram) distribution of systolic blood pressure of study participants (1183) aged $\geq 40$ years in Kabul city, 2012.

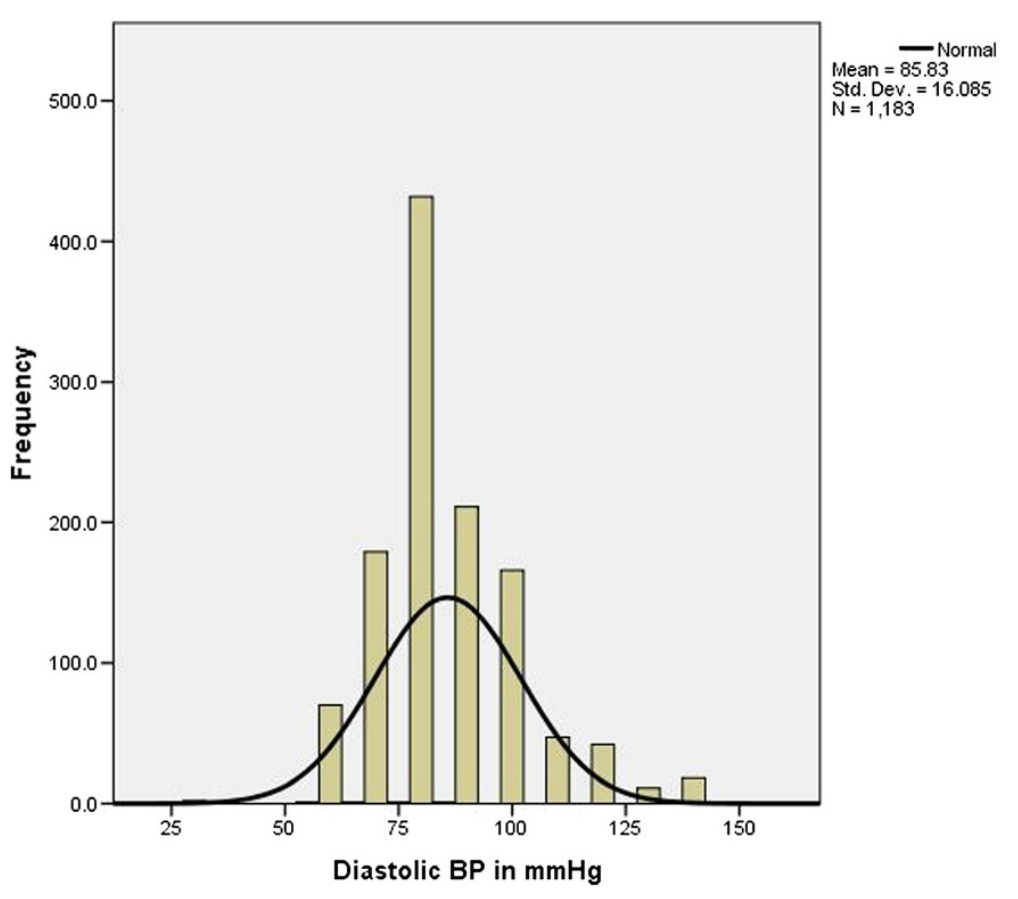

Figure 2 Graphic (histogram) distribution of diastolic blood pressure of study participants (1183) aged $\geq 40$ years in Kabul city, 2012. 
Table 2 Bivariate analysis of bio-demographic, socio economic and behavior risk factors associated with hypertension among Kabul citizens $(n=1183)$

\begin{tabular}{|c|c|c|c|c|}
\hline Variables & Hypertensive & Non-hypertensive & Odds ratio & $\% 95 \mathrm{Cl}$ \\
\hline \multicolumn{5}{|l|}{ Age in years } \\
\hline $40-49$ & $231(33.4)$ & $460(66.6)$ & 1 & Reference \\
\hline $50-59$ & $143(59.1)$ & $99(40.9)$ & 2.87 & $2.13-3.88$ \\
\hline $60-69$ & $112(70.4)$ & 47 (29.6) & 4.74 & $3.26-6.90$ \\
\hline 70 and over & $55(74.3)$ & $19(25.7)$ & 5.76 & $3.43-9.94$ \\
\hline \multicolumn{5}{|l|}{ Sex } \\
\hline Males & $178(44.9)$ & $218(55.1)$ & 1 & Reference \\
\hline Females & $368(46.8)$ & 419 (53.2) & 1.07 & $0.84-1.37$ \\
\hline \multicolumn{5}{|l|}{ Level of education } \\
\hline literate & $363(53.8)$ & $312(46.2)$ & 2.06 & $1.63-2.61$ \\
\hline Illiterate & $183(36.0)$ & $325(64.0)$ & 1 & Reference \\
\hline \multicolumn{5}{|l|}{ Monthly income } \\
\hline$\leq 200$ USD & $247(47.1)$ & $277(52.9)$ & 1.07 & $0.85-1.35$ \\
\hline$>200$ USD & $299(45.4)$ & $360(54.6)$ & 1 & Reference \\
\hline \multicolumn{5}{|l|}{ Work status } \\
\hline Government employee & 90 (34.6) & $170(65.4)$ & 1 & Ref \\
\hline Business & 21 (35.6) & $38(64.4)$ & 1.04 & $0.57-1.88$ \\
\hline Famer & $28(44.4)$ & 35 (55.6) & 1.51 & $0.86-2.64$ \\
\hline Jobless & $245(51.9)$ & $227(48.1)$ & 2.04 & $1.49-2.78$ \\
\hline Housewife & $137(47.2)$ & $153(52.8)$ & 3.37 & $1.67-6.81$ \\
\hline Unable to work & $25(64.1)$ & $14(35.9)$ & 1.69 & $1.20-2.38$ \\
\hline \multicolumn{5}{|c|}{ Knowledge of blood pressure } \\
\hline Yes & $94(48.2)$ & $101(51.8)$ & 1 & Ref \\
\hline No & $452(45.7)$ & $536(54.3)$ & 0.9 & $0.66-1.23$ \\
\hline \multicolumn{5}{|l|}{ Smoking status } \\
\hline Current smoker & $23(37.7)$ & $38(62.3)$ & 0.72 & $0.42-1.22$ \\
\hline Ever smoker & $51(53.7)$ & $44(46.3)$ & 1.37 & $0.90-2.10$ \\
\hline Never smoker & $465(45.7)$ & $553(54.3)$ & 1 & Reference \\
\hline \multicolumn{5}{|l|}{ Snuff using } \\
\hline Current user & $58(55.2)$ & $47(44.8)$ & 1.51 & $1.01-2.26$ \\
\hline Ever user & $13(52.0)$ & $12(48.0)$ & 1.32 & $0.59-2.93$ \\
\hline Never user & $469(45.0)$ & $574(55.0)$ & 1 & Reference \\
\hline \multicolumn{5}{|c|}{ Walking by foot to work station } \\
\hline No & $214(49.3)$ & $220(50.7)$ & 1.22 & $0.96-1.55$ \\
\hline Yes & $331(44.3)$ & $416(55.7)$ & 1 & Reference \\
\hline \multicolumn{5}{|l|}{ Going by car to work } \\
\hline No & $523(47.1)$ & $587(52.9)$ & 1.89 & $1.14-3.15$ \\
\hline Yes & $23(31.9)$ & $49(68.1)$ & 1 & Reference \\
\hline \multicolumn{5}{|c|}{ Going by public Transport to work } \\
\hline No & $528(47.0)$ & $596(53.0)$ & 2.01 & $1.14-3.55$ \\
\hline Yes & $18(30.5)$ & $41(69.5)$ & 1 & Reference \\
\hline \multicolumn{5}{|l|}{ Diabetes mellitus } \\
\hline No & $455(44.3)$ & $571(55.7)$ & 1 & Reference \\
\hline Yes & $91(58.0)$ & $66(42.0)$ & 1.7 & $1.23-2.43$ \\
\hline
\end{tabular}


Table 2 Bivariate analysis of bio-demographic, socio economic and behavior risk factors associated with hypertension among Kabul citizens ( $\mathbf{n}=1183$ ) (Continued)

\begin{tabular}{|c|c|c|c|c|}
\hline \multicolumn{5}{|c|}{ General obesity cut off $\mathrm{BMI}=30$} \\
\hline No & $324(40.3)$ & $480(59.7)$ & 1 & Reference \\
\hline Yes & $222(58.6)$ & $157(41.4)$ & 1.73 & $1.23-2.43$ \\
\hline \multicolumn{5}{|l|}{ Central obesity B } \\
\hline No & $169(35.1)$ & $312(64.9)$ & 1 & Reference \\
\hline Yes & $370(53.9)$ & $317(46.1)$ & 2.15 & $1.69-2.73$ \\
\hline \multicolumn{5}{|c|}{ Frequency of eating rice in a month } \\
\hline$\leq 6$ times per month & $439(45.4)$ & $529(54.6)$ & 1 & Reference \\
\hline$>6$ times/month & $44(34.9)$ & $82(65.1)$ & 1.54 & $1.05-2.27$ \\
\hline \multicolumn{5}{|c|}{ Frequency of walking per week in hours } \\
\hline$<10$ hours per week & $202(53.9)$ & $173(46.1)$ & 1 & Reference \\
\hline 10-30 hours/week & $274(43.8)$ & $351(56.2)$ & 0.66 & $0.51-0.86$ \\
\hline$\geq 30$ hours/week & 68 (38.6) & $108(61.4)$ & 0.50 & $0.37-0.77$ \\
\hline
\end{tabular}

Table 3 Multivariable analysis risk factors associated with hypertension among Kabul citizens $(n=1183)$

\begin{tabular}{llll}
\hline Variables & Adjusted OR & $\% 95 \mathrm{Cl}$ & P Value \\
\hline Age group & & & \\
$\leq 50$ & 1 & Reference & - \\
$>50$ & 3.86 & $2.86-5.21$ & $<0.001$
\end{tabular}

\section{Education level}

Literate

Illiterate

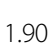

References

$1.05-1.90$

$<0.05$

Having rice as meal

$\leq 3$ times a week

$>3$ times a week

1

1.43

References

$1.07-1.91$ $<0.05$

\section{Having chicken as meal}

$\leq 3$ times a month

0.73

$>3$ times a month

0.73

Family history of diabetes
No

Yes
References

$0.55-0.97$ $<0.05$

References

$1.30-3.75$ $<0.05$

Taking fruits with meal

stwice a week 1

$>$ twice a week

0.64

Central obesity

No

Yes

1

1.67

General obesity as BMI cut off 30

\begin{tabular}{llll} 
No & 1 & References & - \\
Yes & 2.08 & $1.50-2.89$ & $<0.001$ \\
\hline
\end{tabular}

and low socio-economic status were associated with increase odds of hypertension [11]. Other studies in Iran, Turkey, Sri Lanka, Angola and China found similar findings that older age, high blood glucose level, lower level of education, retirement/unemployment and higher body mass index were significantly associated with hypertension [12-17].

Literacy was an independent predictor of hypertension but the association between education and health is a complex one. Though in some settings it may be a marker of (and confounded by) socio economic status, there is no doubt that literacy enhances health awareness an association that has been demonstrated in numerous studies. To this effect, literacy was selected as a target for the Millennium Development Goals by the WHO and UN $[11,18,19]$. In Afghanistan, as a result of political forces the provision of universal literacy has been complex and challenging. This has been most marked for girls but, at the time of writing, the country is for the first time holding independent elections and we can only hope that education is marked as a priority for the new government.

The other predictors, sedentary lifestyle, obesity and impaired glucose tolerance are all potentially amenable to intervention at a public health level. Sedentary lifestyles may stem from a lack of activity in school. If education were to be available universally and physical activity a mandatory part of the school day, there is every reason to believe that this can be inculcated from an early age for life. Though there may be cultural sensitivities, they can be overcome as Almas and colleagues demonstrated in an innovative study in urban Pakistan [20]. Other than education, better use of the media to inform the population has a role particularly as most households now have at least a television. Subsidising blood pressure checks in primary medical care would additionally 
encourage update of screening. We feel that, given our findings, both mass and targeted intervention would be feasible. We have shown that Afghanistan is equally at risk of hypertension and has the same risk factors as other populations. As the conflict subsides, our attention must turn to another threat, that of the non-communicable diseases epidemic.

\section{Conclusion}

Though instability has hitherto precluded detailed study, this unique study has shown that hypertension and obesity is at epidemic proportions in household adults in Kabul. As Afghanistan enters a new era, intervention is now a Public Health priority.

\section{Competing interests}

There is no financial or non-financial competing interest of authors in this paper.

\section{Authors' contributions}

KMIS has been involved in conception, design, and implementation and reporting of the study. MHR has been involved in analysis and report writing while NB has reviewed the whole paper including analysis and interpretations. He has copy edited the manuscript to get ready for publication. All authors read and approved the final manuscript.

\section{Acknowledgement}

We would like to thank Dr Jawad Asgar, FELTP Advisor and Dr Jamil Ansari Senior Instructor of FELTP in Pakistan for their contribution in design of the study. In addition the Eastern Mediterranean Public Health Training Network (EMPHNET) is thanked for their assistance in contribution of data via data analysis course in Amman in 2012.

\section{Author details}

'Surveillance/DEWS Directorate, Afghan National Public Health Institute (ANPHI), Ministry of Public Health, 3rd Floor, Room \# 9, Massoud Square, Kabul, Afghanistan. ${ }^{2}$ Salisbury District Hospital Visiting Faculty, Salisbury, Wiltshire, UK. ${ }^{3}$ Aga Khan University, Karachi, Pakistan. ${ }^{4}$ Southampton University Hospitals Trust Visiting fellow, University of Southampton, Southampton, Hampshire, UK.

Received: 14 July 2013 Accepted: 14 April 2014

Published: 23 April 2014

\section{References}

1. Kearney PM, Whelton M, Reynolds K, Muntner P, Whelton PK, He J: Global burden of hypertension: analysis of worldwide data. Lancet 2005, 365(9455):217-223.

2. Fauci S, Braunwald E, Kasper DL, Hauser SL, Longo DL, Jameson JL, Loscalzo $J$ : Harrison's principles of Internal Medicine. In Factors that contribute to High Blood Pressure: The American Heart Association. 17th edition. New York, USA: The McGraw-Hill Companies; 2008.

3. World Health Organization: 2008-2013 Action Plan for the Global Strategy for the Prevention and Control of Non-communicable Diseases. Geneva Switzerland: World Health Organization Press; 2008.

4. Kearney PM, Whelton M, Reynolds K: Worldwide prevalence of hypertension: a systematic review. J Hypertens 2004, 22:11-19.

5. Central Statistics Organization, Islamic Republic of Afghanistan, Population Statistics: Population Estimation 2012-2013. Kabul-Afghanistan: CSO Press; 2012. Available online at: http://cso.gov.af/fa/page/demography-and-socile-statistics/ demograph-statistics/3897.

6. Jose Aponte J, Brown D, Collins H, Copeland J, Haines J, Islam A, Jones G, Knudsen E, Mir R, Nitschke D, Worsham C: Epi Info [computer program]. Version 3.5.1. NY, USA: Centers for Disease Control and Prevention (CDC); 2008
7. World Health Organization: Obesity: Preventing and Managing the Global Epidemic. Geneva: World Health Organization; 2000. WHO Technical Report Series No.894.

8. Alberti SG, Zimmet P: The IDF Consensus Worldwide Definitions of the Metabolic Syndrome. Brussels, Belgium: International Diabetes Federation; 2006. Available online: http://www.idf.org/webdata/docs/MetS_update2006.pdf.

9. IBM Corp.: IBM SPSS Statistics for Windows [computer program]. Version 20.0 Armonk, NY: IBM Corp.; 2011.

10. Veghari G, Sedaghat M, Maghsodlo S, Banihashem S, Moharloei P, Angizeh A, Tazik E, Moghaddami A: Impact of literacy on the prevalence, awareness, treatment and control of hypertension in adults in Golestan Province (northern Iran). Caspian J Int Med 2013, 4(1):580-584.

11. Pires JE, Sebastiao YV, Langa AJ, Nery SV: Hypertension in Northern Angola: prevalence, associated factors, awareness, treatment and control. BMC Public Health 2013, 13(1):90.

12. Sit JW, Sijian L, Wong EM, Yanling Z, Ziping W, Jianqiang J, Yanling C, Wong TK: Prevalence and risk factors associated with prehypertension: identification of foci for primary prevention of hypertension. J Cardiovasc Nurs 2010, 21(6):461-469.

13. Meshram II, Arlappa N, Balkrishna N, Rao KM, Laxmaiah A, Brahmam GN: Prevalence of hypertension, its correlates and awareness among adult tribal population of Kerala state, India. J Postgrad Med 2012, 58(4):255-261.

14. Ordinioha B: The prevalence of hypertension and its modifiable risk factors among lecturers of a medical school in Port Harcourt, south-south Nigeria: implications for control effort. Niger J Clin Pract 2013, 16(1):1-4 doi:10.4103/1119-3077.106704

15. Baltaci D, Erbilen E, Turker Y, Alemdar R, Aydin M, Kaya A, Celer A, Cil H, Aslantas $Y$, Ozhan $\mathrm{H}$ : Predictors of hypertension control in Turkey: the MELEN study. Eur Rev Med Pharmacol Sci 2013, 17(14):1884-1888.

16. Ibrahim KR, Nariman A, Hijazi NA, Al- Bar AA: Prevalence and Determinants of Prehypertension and Hypertension among Preparatory and Secondary School Teachers in Jeddah. J Egypt Public Health Assoc 2008, 83(14):183-203.

17. Katulanda P, Ranasinghe $P$, Jayawardena $R$, Constantine GR, Rezvi Sheriff $\mathrm{MH}$, Matthews DR: The prevalence, predictors and associations of hypertension in Sri Lanka: a cross-sectional population based national survey. Clin Exp Hypertens 2014, Epub ahead of print.

18. Veghari G, Sedaghatb M, Maghsodlob S, Banihashemb S, Moharloeib P, Angizehb A, Tazikb E, Moghaddamib A: Influence of education in the prevalence of obesity in Iranian northern adults. J Cardiovasc Dis Res 2013, 4(1):30-33. doi:10.1016/j.jcdr.2013.02.002.

19. Khan RJ, Stewart CP, Christian P, Schulze KJ, Wu L, LeClerq SC, Khatry SK, West KP: A cross-sectional study of the prevalence and risk factors for hypertension in rural Nepali women. BMC Public Health 2013, 13:55.

20. Almas A, Islam M, Jafar T: School-based physical activity programme in preadolescent girls (9-11 years): a feasibility trial in Karachi, Pakistan. Arch Dis Child 2013, 98(7):515-519.

doi:10.1186/1471-2458-14-386

Cite this article as: Saeed et al:: Prevalence and predictors of adult hypertension in Kabul, Afghanistan. BMC Public Health 2014 14:386.

\section{Submit your next manuscript to BioMed Central and take full advantage of:}

- Convenient online submission

- Thorough peer review

- No space constraints or color figure charges

- Immediate publication on acceptance

- Inclusion in PubMed, CAS, Scopus and Google Scholar

- Research which is freely available for redistribution 